\title{
Comparison of two land surface schemes in week-long cloud-system-resolving simulations of warm season precipitation
}

\author{
Changhai Liu $\cdot$ Jimy Dudhia $\cdot$ Mitchell W. Moncrieff
}

Received: 26 July 2007/ Accepted: 5 March 2010/Published online: 25 March 2010

(C) Springer-Verlag 2010

\begin{abstract}
This paper presents a case study of the impact of land surface treatment on warm season precipitation simulations at convection-permitting grid resolution. Two surface schemes are tested: Dudhia's five-layer soil model (FLSM) and the Noah land-surface model (NLSM). The experimentation case involves a 1-week episode of active summertime convection over the central United States. The overall precipitation features, such as the diurnal regeneration of zonally propagating rainfall episodes and the spatial distribution of accumulative rainfall, are adequately replicated by the two parameterizations. In comparison, NLSM produces roughly $12 \%$ more and broader rainfall than FLSM. This differential rainfall amount is consistent with the differential surface moisture fluxes between the two schemes, whereas the precipitation feedback plays a negligible role. It is also found that FLSM generates comparatively stronger sensible heat transports from the land surface and thus a warmer temperature near the surface.
\end{abstract}

\section{Introduction}

Land-surface processes affect warm-season precipitating systems through heat and moisture exchanges between the surface and overlying atmosphere. During the past few decades, a number of land-surface schemes of various

\section{Liu}

Institute of Heavy Rain, China Meteorological Administration,

Wuhan, China

C. Liu $(\bowtie) \cdot$ J. Dudhia $\cdot$ M. W. Moncrieff

National Center for Atmospheric Research, P. O. Box 3000,

Boulder, CO 80307-3000, USA

e-mail: chliu@ucar.edu degrees of sophistication have been developed, such as single-layer force-restore (Blackadar 1976), multi-layer thermal diffusion (Dudhia 1996), and land-surface models with soil moisture prediction and vegetation effects (e.g., Chen and Dudhia 2001). Because of the wide variety of schemes currently being used, a natural concern is the sensitivity of the prediction and simulation of warm-season precipitation in high-resolution numerical models to the land-surface parameterization. Another important issue is whether realism is consistently improved with increasingly sophisticated land-surface processes. Addressing these problems is not only of practical significance, but also helpful in guiding the future improvement and development of land-surface parameterizations.

The present study focuses on the diurnal regeneration and propagation characteristics of warm-season precipitating systems. This important climatological aspect of midsummer convection over the Continental United States has been comprehensively documented from radar-based observations (Carbone et al. 2002). Herein, we evaluate the sensitivity of multi-day cloud-system-resolving explicit simulations to two land-surface schemes with emphasis on the precipitation characteristics.

For short-range simulations of up to about 2 days, the land-surface model's main value is in modulating diurnal effects based on the soil properties. The primary sensitivity is to the initial soil moisture that determines the Bowen ratio partitioning between sensible and latent heat flux and induces mesoscale circulations in response to horizontal gradients of sensible heat fluxes, which in turn helps in determining boundary layer properties that might influence the timing and location of convective development (e.g., Zhang and Anthes 1982; Lanicci et al. 1987; Segal et al. 1995; Shaw et al. 1997). On the other hand, for long-range simulations, such as in regional climate multi-month 
simulations, the value of the land-surface model is in the prediction of the temporal evolution of surface properties, mainly that of the soil moisture which is likely to be a key component of interannual variability in a given season (e.g., Zhang et al. 2008). However, in the multi-day range, it is still less clear that the time variability in the soil is critical. A recent case study for a 12-day warm-season period demonstrated that the initial soil wetness and land surface scheme have more significant impacts on the mean regional-scale near-surface thermodynamics than evolving soil moisture (Trier et al. 2008). The purpose of this study is to investigate whether multi-day convective studies are sensitive to the temporal soil variation given by sophisticated land-surface models.

\section{Numerical model and experimental setup}

We use the latest nonhydrostatic version of the Pennsylvania State University/National Center for Atmospheric Research mesoscale model (MM5) (Dudhia et al. 2003). The $2,400 \times 1,800 \mathrm{~km}^{2}$ computational domain encompasses approximately two-thirds of the continental US with $3-\mathrm{km}$ grid spacing (Fig. 1). There are 40 vertical levels unevenly spaced from $\sim 2.5 \mathrm{hPa}$ near the surface to $50 \mathrm{hPa}$. All simulations employ the planetary boundary layer scheme adapted from that in the National Centers for Environmental Prediction (NCEP) medium-range forecast model (Hong and Pan 1996), the Goddard Space Flight Center five-class mixed-phase microphysics scheme (Tao and Simpson 1993), and the longwave and shortwave parameterization based on Dudhia (1989).

Two land surface schemes are tested to investigate how the warm-season precipitation forecasts depend on the

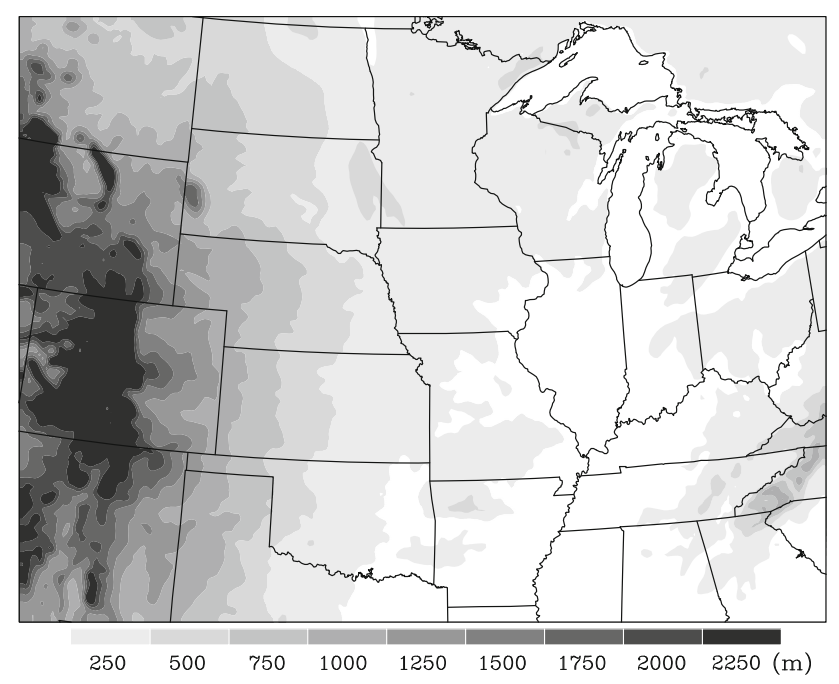

Fig. 1 Terrain of the computational domain treatment of land-surface processes. The first is the fivelayer soil model (hereafter FLSM) developed by Dudhia (1996). This model provides an improvement in the ground temperature prediction over that produced by the two-layer force-restore method (Blackadar 1976) at minimal computational cost. However, it retains the simplicity of predicting just the thermal budget of the soil layers, ignoring soil moisture and vegetation effects. The surface latent heat flux is determined based on the moisture availability that has only land-use and summer/winter dependencies, so there is no soil water budget. The second scheme is the Noah land-surface model (hereafter NLSM), which is a modified after the Oregon State University land surface model (Chen and Dudhia 2001) and closely related to that used in the NCEP global and regional forecast models. This scheme has four layers of soil temperature and soil moisture, and also predicts canopy moisture and snow cover. It has land-use-dependent vegetation effects accounting for stomatal and root zone effects on evapotranspiration soiltype-dependent sedimentation and run-off effects in the soil moisture budget.

The case selected for study is a 7-day warm season heavy precipitation episode over the central United States from 0000 UTC 3 July to 0000 UTC 10 July 2003. During this 1-week period, a nearly zonal westerly flow prevails in the upper troposphere over the northern US, superimposed upon with east-traveling short wave activities (Liu et al. 2006; Trier et al. 2006). A regular daily regeneration of eastward-propagating mesoscale convective systems (MCSs) occurs in the lee of the Rockies. This multi-day pattern has previously been simulated: (1) to evaluate the capabilities of explicit convection-permitting models in predictions of summertime precipitation (Liu et al. 2006), (2) to address the parameterization issue relevant to the mesoscale organization of precipitating convection (Moncrieff and Liu 2006), (3) to examine the mechanisms associated with long-lived propagating convection (Trier et al. 2006), and (4) to quantify the effects of cloud microphysics parameterizations (Liu and Moncrieff 2007). Herein, a total of three numerical experiments are conducted that differ only in the treatment of land surface processes, corresponding to the application of NLSM, FLSM, and NLSM excluding precipitation feedbacks (hereafter referred to as NLNF), respectively. NLNF differs from the full land-surface run (NLSM) only in that it keeps the soil moisture constant at its initial value, excluding the effects of moistening, mostly due to precipitation, and drying due to surface evaporation and drainage. The purpose of NLNF is to evaluate the time dependence of soil moisture and particularly the short-term effect of the water cycle between precipitation events. As in our aforementioned previous studies of this case, the initial conditions, including those for soil moisture for the NLSM and NLNF 
experiments, and lateral boundary conditions are obtained from the 3-hourly, 40-km grid spacing NCEP operational ETA model analyses.

\section{Results}

Figure 2 compares the 7-day accumulative rainfall distributions in the three simulations with radar analysis. The radar-derived rainfall in Fig. 2a is based on a reflectivityrain relationship, $Z=300 R^{1.5}$, where $Z$ and $R$ are the radar reflectivity and rainrate, respectively (Carbone et al. 2002). Although it has desirable spatial and temporal resolution ( $\sim 2 \mathrm{~km}$ in space and $15 \mathrm{~min}$ in time), this dataset features significant uncertainty with regard to quantitative precipitation estimation. The observed heavy precipitation has a largely zonally oriented distribution contained within a narrow zone, extending from the lee of the Rockies across the Great Plains. The heaviest rainfall is located in Iowa, stretching east-south-eastward into Indiana and Ohio. All simulations (Fig. 2b-d) produce an approximately WNWESE concentrated precipitation band, bearing a strong resemblance to the radar analysis except for the too-far southward-tilted distributions as compared to the nearly east-west orientation in the radar observations. This meridional position error is associated with the tendency of the forecasted organized convective systems to travel to the right (southern flank) of their observed counterparts. Interestingly, a similar bias in the propagation direction was reported in explicit forecasts with the weather research and forecasting (WRF) model at 4-km grid spacing (Done et al. 2004). Because this deficiency appeared in both MM5 and WRF simulations, it is possibly attributable to the errors in the forcing data, the ETA forecast, which was used to provide initial and boundary conditions for the two models. Another common discrepancy among these simulations is the too-weak intensity and too-widespread distribution in the east portion of the precipitation corridor. In addition, the model misses or underpredicts (overpredicts) the weak rainfall near the southwest (northeast) corner of the computational domain. Visually, NLSM and NLNF are comparable, and the influence of precipitation feedbacks in NLSM is minimal. The domain-averaged accumulated rainfall is $34.7 \mathrm{~mm}$ for radar estimate, and is 33.4, 29.8 and $33.2 \mathrm{~mm}$ for simulations using NLSM, FLSM and NLNF, respectively. Both NLSM and NLNF produce about $12 \%$ more rainfall than FLSM and are also closer to the radarderived value.

Figure 3 details the spatial distribution of differential rainfall amount between each pair of simulations. Even though the accumulative rainfall displays similar spatial patterns among the three simulations, the local difference can still be more than $50 \mathrm{~mm}$ inside the concentrated precipitation corridor. The difference is relatively small outside the heavy precipitation region. Careful inspection shows that NLSM generates stronger rainfall than FLSM over a majority of grid points, especially, over the light rainfall regions (Fig. 3a) (the ratio of grid boxes with a positive and negative rainfall anomaly is 1.32). This is in agreement with the aforementioned larger domain-
Fig. 2 Accumulated rainfall amount during the 7 days. a Radar estimate, and b-d simulations applying Noah land surface model, five-layer soil model, and Noah land surface model without precipitation feedback, respectively
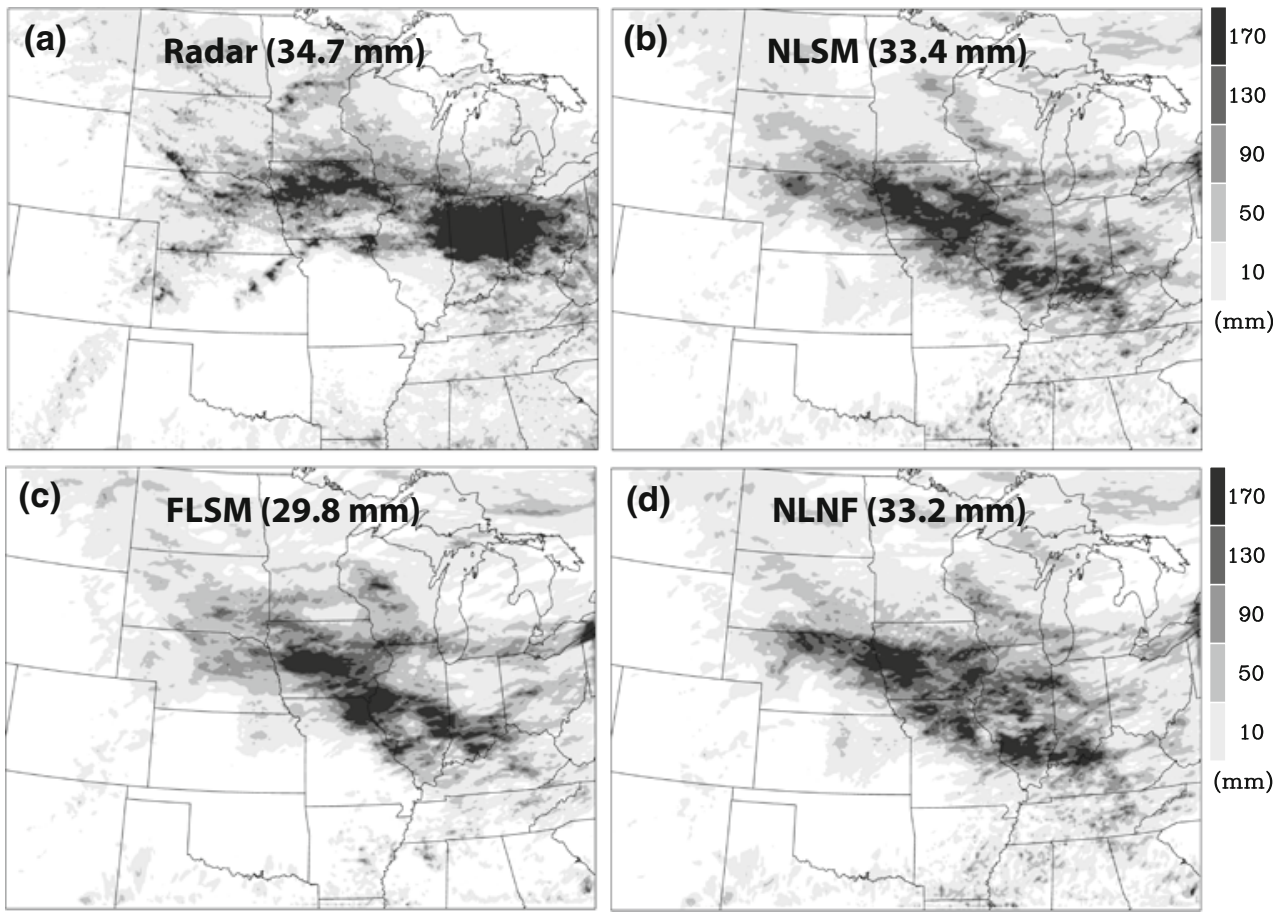


\section{(a) NLSM - FLSM}

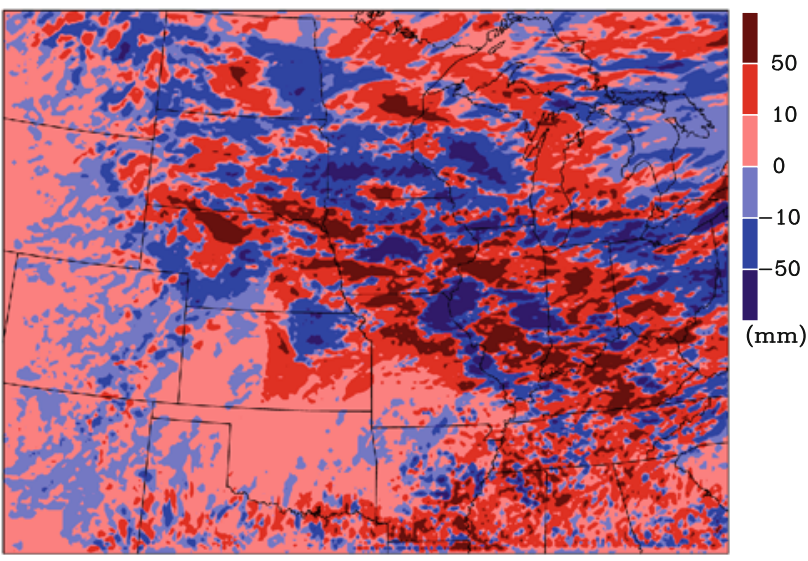

(b) NLSM - NLNF

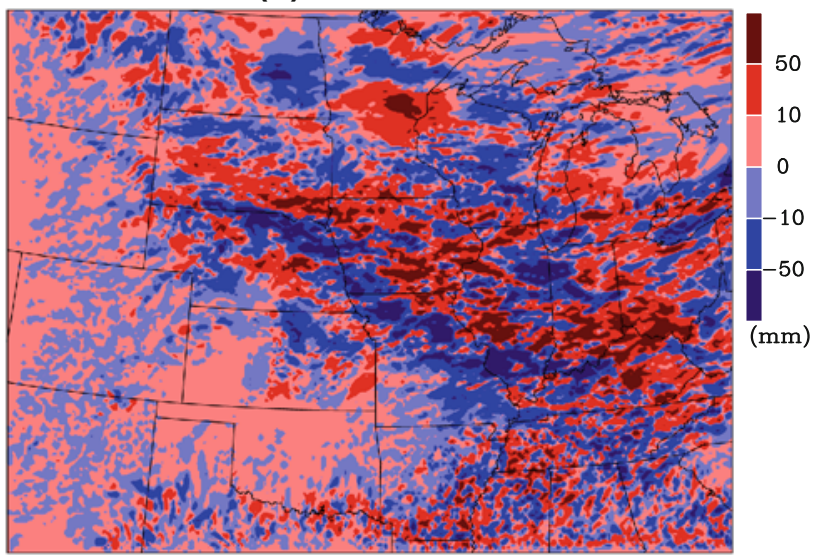

Fig. 3 Differential accumulative rainfall between a simulations using Noah land surface model and five-layer soil model and $\mathbf{b}$ simulations using Noah land surface model with and without precipitation feedback

averaged value for the simulation using NLSM. As indicated in Fig. 3b, heavy rainfall shifts southward when precipitation feedback is excluded, but the numbers of grid points with a positive or negative anomaly are almost identical.

All simulations reasonably capture the temporal and spatial sequences of propagating convection as displayed in the time-longitude depiction of meridionally-averaged rainfall rate (not shown). Figure 4 displays the corresponding diurnal Hovmoller diagrams of rain rate averaged over the 7-day period. Two parallel concentrated downward-sloping rainfall signatures (streaks) in the radar composite (Fig. 4a) originate in the neighborhood of the Continental Divide about 21 UTC. Spanning a sizable fraction of the continent with propagation speed of roughly $21 \mathrm{~ms}^{-1}$, they represent the week-long mean behavior of successive zonally propagating precipitation episodes. On the whole, the surface schemes have equal skill in predicting these coherent rainfall patterns and have similar
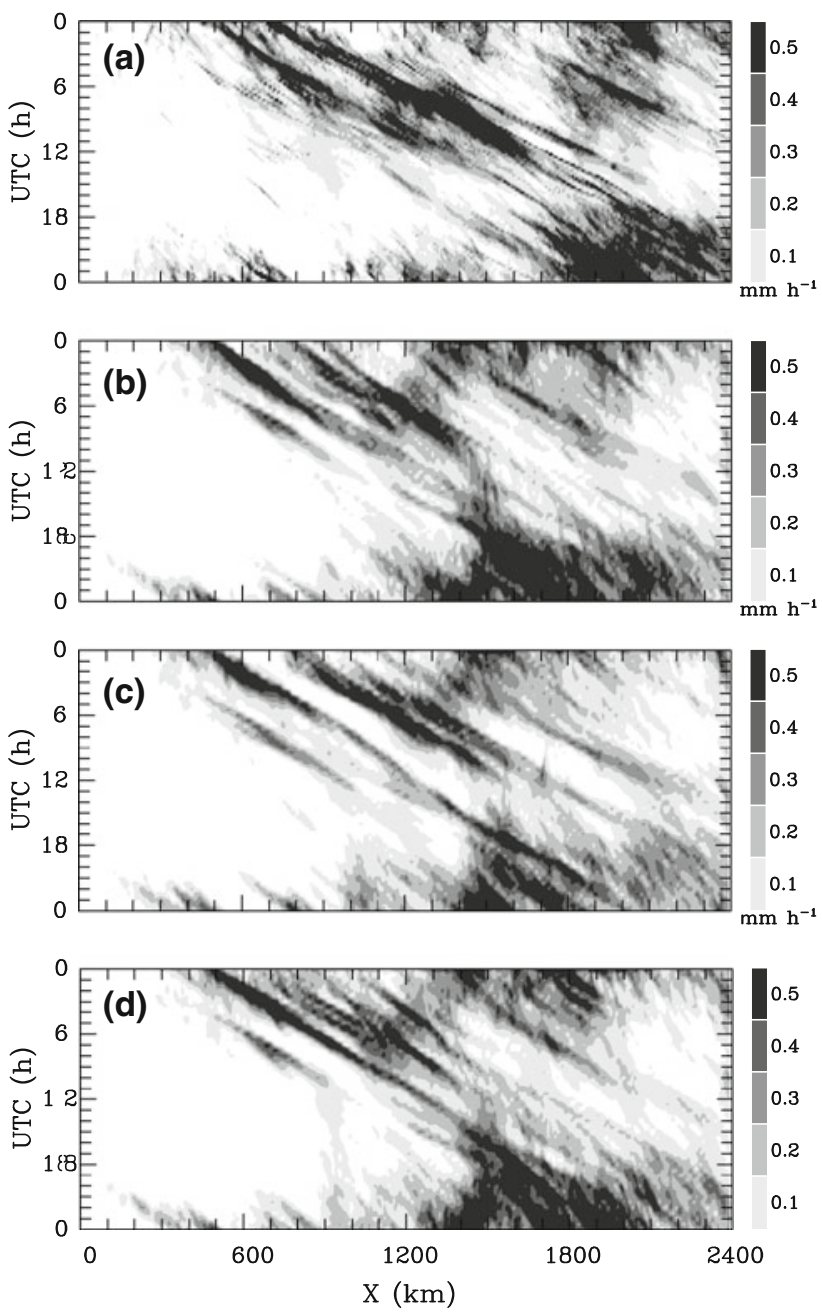

Fig. 4 The 7-day composite diurnal Hovmoller diagrams of meridionally averaged surface rainfall rate. a Radar observations, and b-d simulations using Noah land-surface model, five-layer soil model, and Noah land-surface model without precipitation feedback, respectively

discrepancies too. The most noticeable deficiency is the dearth of heavy rainfall near the eastern boundary because the modeled rainfall is located too far west. This is especially problematic in the simulation operating FLSM. A similar problem is encountered with a 4-km-resolution simulation with the WRF model (Trier et al. 2006), likely attributable to the too-coarse grid spacing (Moncrieff and Liu 2006).

Figure 5 compares the evolution of the simulated domain-averaged rainfall rate and fractional area with the respective observation counterpart. The temporal variations in rainfall amount resemble each other and show distinct diurnal oscillations with a late-afternoon (around 00 UTC) maximum and early morning (around 12 UTC) minimum during most of the 1-week period (Fig. 5a). Qualitatively, the results are in agreement with the radar estimate except for the first day during which the rainfall is overpredicted. 

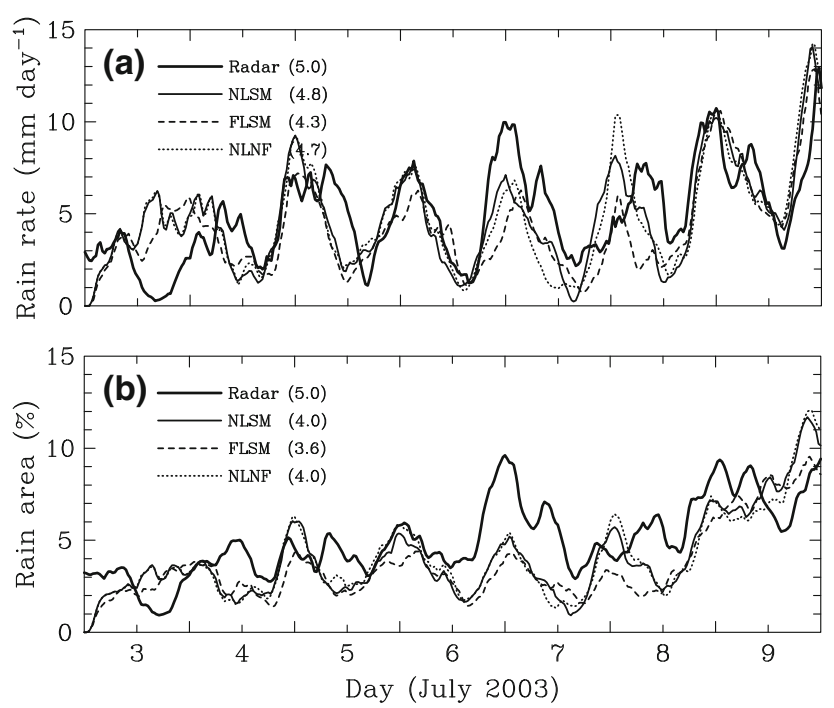

Fig. 5 Evolution of a domain-averaged rainfall rate and $\mathbf{b}$ rainfall areal fraction for radar estimate (thick solid) and simulations using Noah land-surface model (solid), five-layer soil model (dashed), and Noah land-surface model without precipitation feedback (dotted), respectively

The 7-day means are about 4.8, 4.3 and $4.7 \mathrm{~mm} \mathrm{day}^{-1}$ for simulations using NLSM, FLSM and NLNF, respectively, slightly smaller than the observed value of $5 \mathrm{~mm}^{\text {day }}{ }^{-1}$. Consistent with the differential accumulative rainfall discussed above, there is a roughly $12 \%$ difference in rain rate between the two land-surface schemes. Similarly, the variability in rainfall area (Fig. 5b) is insensitive to the landsurface parameterization, but show more discrepancies from radar observations. In calculating rainfall areal fraction, it is assumed that precipitation occurs over a grid box when the 30-min accumulated rainfall exceeds an intensity of $0.1 \mathrm{~mm} \mathrm{~h}^{-1}$. All simulations underpredict the observed values, but overpredict the diurnal amplitudes. This deficiency is likely associated with insufficient resolution to correctly represent convective initiation under weakly forced conditions. On an average, the rain areal coverage is $5,4,3.6$ and $4 \%$ for radar estimates, NLSM, FLSM and NLNF, respectively, equating to a difference of about $11 \%$ between the two land-surface parameterizations. The similarity between the NLSM and NLNF simulations also gives a measure of the magnitude of random internal model variability, demonstrating that these differences from FLSM are probably robust in a statistical sense.

Figure 6 presents the evolution of the domain-averaged surface sensible and latent heat fluxes. As expected, the sensible heat fluxes exhibit strong upward transport from the underlying warm surface during the daytime and weak downward transport during the nighttime, synchronous with the solar radiation. The daytime maximum occurs around 18 UTC, whereas the nocturnal negative flux is rather small and uniform. In general, FLSM consistently
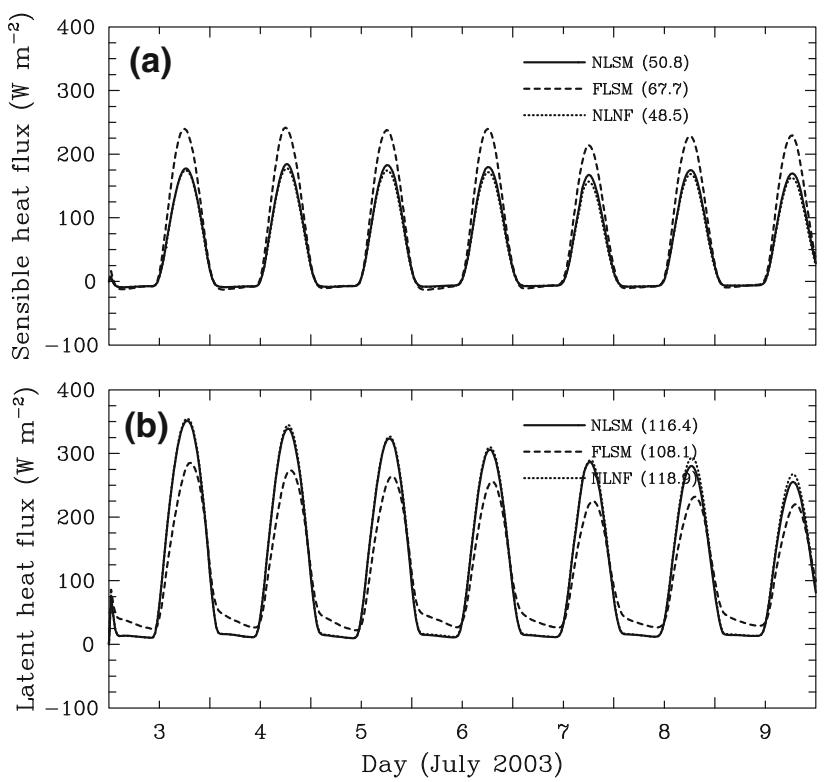

Fig. 6 Evolution of a domain-averaged surface sensible heat fluxes and b latent heat fluxes for simulations using Noah land-surface model (solid), five-layer soil model (dashed), and Noah land-surface model without precipitation feedback (dotted), respectively

produces a greater (slightly smaller) sensible heat flux than NLSM during the daytime (night) with a temporally averaged difference of about $17 \mathrm{~W} \mathrm{~m}^{-2}$. In contrast, NLSM produces more (less) latent heat fluxes during the daytime (nighttime) and thus more salient daily variabilities. Additionally, there is a minor timing difference in the maximum. The 7-day mean value is roughly $8.3 \mathrm{~W} \mathrm{~m}^{-2}$ larger in NLSM than in FLSM. This moisture flux difference is equivalent to a difference of about $0.26 \mathrm{~mm}_{\text {day }}{ }^{-1}$ precipitation difference had all the differential moisture rained out: about half the precipitation difference between the two schemes. The mean Bowen ratio is 2.3 and 1.6 for NLSM and FLSM, respectively.

Figure 7 displays the evolution of the temperature and water vapor mixing ratio at the lowest model level (about $25 \mathrm{~m}$ above ground level). In response to the surface energy uptake, the near-surface temperature undergoes a significant diurnal oscillation with a peak around 21.5 UTC and a minimum around 11.5 UTC. Obviously, FLSM corresponds to consistently warmer temperature than both NLSM and NLNF, with an averaged difference of approximately $0.8 \mathrm{~K}$, consistent with the differential sensible heat transports (Fig. 6a). The maximum difference occurs in the late afternoon and evening, which, as expected, lags the corresponding maximum difference in sensible heat flux by a few hours. The near-surface water vapor also experiences significant daily fluctuation, but the variational pattern differs considerably between the two surface schemes. A striking diurnal cycle is present in FLSM, whereas NLSM or NLNF generates a less-pronounced daily maximum. In all the 

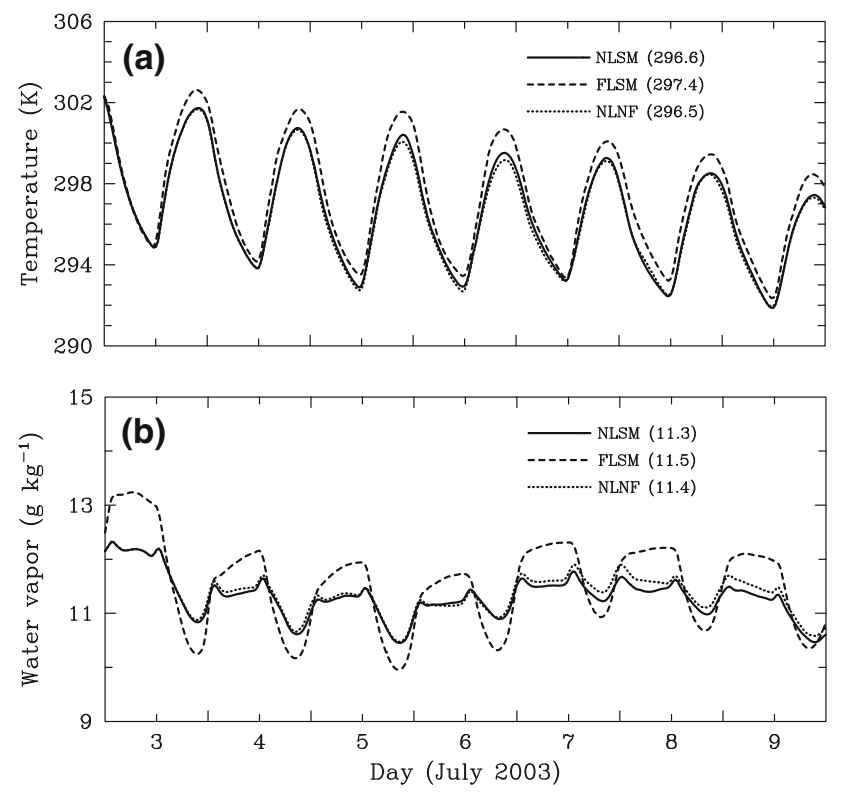

Fig. 7 Evolution of a domain-averaged temperature and $\mathbf{b}$ water vapor mixing ratio at the lowest model level $(\sim 25 \mathrm{~m}$ above the ground) for simulations using Noah land-surface model (solid), fivelayer soil model (dashed), and Noah land-surface model without precipitation feedback (dotted), respectively

simulations, the lowest-level water vapor dries as the boundary layer grows in the morning, presumably due to the PBL scheme mixing drier air downwards. The water vapor recovers later as the surface moisture restores it to an equilibrium value. NLSM has a much reduced diurnal cycle, and additionally has a diurnal cycle in soil moisture (not shown) with a minimum at dusk. NLNF shows that the NLSM diurnal cycle is influenced little by the soil moisture variation, in agreement with Trier et al.'s finding that the soil moisture evolution has negligible effects on near-surface thermodynamics for a 12-day period. The morning drying is less with the NLSM probably due to the higher latent heat flux, and possibly because the reduced sensible heat flux leads to reduced boundary-layer growth and entrainment of drier air from the top of the PBL. The nighttime moistening is also less which is consistent with the reduced latent heat flux. Nevertheless, the temporal averages show not much difference among the simulations.

\section{Concluding discussion}

We investigated the dependence of cloud-system-resolving simulations of warm season convection on the choice of land-surface schemes in a multi-day case study. The selected case is a 7-day episode in midsummer and characterized by daily genesis of convection east of the Rocky
Mountain and, thereafter, upscale development and propagation toward the plains.

For the most part, the successive heavy rainfall sequences and the spatial distribution of accumulated rainfall are insensitive to the surface scheme. The two schemes perform comparably in capturing the rainfall corridor: daily convective generation near the continental divide and subsequent eastward propagation. They also display similar deficiencies, such as the too-weak and toowidespread precipitation over the eastern portion of the computational domain compared to radar observations.

In comparison, the NLSM produces about $12 \%$ more rainfall and a similarly larger rainfall areal fraction. The differential rainfall amount is consistent with the differential moisture transport from the land surface, specifically an $8 \%$ greater latent heat flux. On the other hand, the FLSM generates greater sensible heat fluxes, which contributes to the warmer temperature near the surface. It is also noted that the precipitation feedback to latent heat fluxes has little impact on the surface water vapor fluxes and thus the boundary-layer properties and overall rainfall intensity, but does affect the detailed precipitation distribution. The FLSM used a specified moisture availability that made its average behavior emulate a drier surface than the LSM. A larger moisture availability could give a closer domain-averaged result, as discussed for the MM5 model's two-layer Blackadar scheme by Oncley and Dudhia (1995); however, it is not clear how to tune moisture availability as a spatial function, because it likely depends on both soil moisture and vegetation type.

The above conclusions are obtained from a single weeklong simulation. Without question, multiple cases under various synoptic conditions are required before these findings can be properly generalized. In particular, the oneweek period in the present study corresponds to moderate large-scale forcing (Liu et al. 2006). We anticipate that under weaker synoptic forcing, typical during the summertime, the convective activity might be more dependent on the interactions between the land surface and the overlying planetary boundary layer and, therefore, more sensitive to the treatment of land surface processes. Furthermore, interannual variability likely depends on the large-scale soil moisture distribution dependent on precipitation over several months prior to the season of interest. Our study focused on a single season and the short time-scale variability of the soil moisture.

The weak sensitivity of propagating organized convection to land-surface parameterization as well as the comparable level of sensitivity to cloud-microphysics parameterization shown in Liu and Moncrieff (2007) was anticipated. However, this does not mean that these parameterizations are unimportant in short-range weather forecasting. As demonstrated, they have non-negligible 
impacts on the simulated cloud and precipitation properties, such as cloudiness, rainfall spectrum, rainfall rate and areal coverage, and therefore are important for quantitative precipitation forecasting. The anticipation of weak sensitivity was based on how convective dynamics is controlled and modulated by environmental wind shear and scale interaction effects embraced by the concept of convective organization (see Moncrieff and Liu 2006 and papers cited therein). Note that the representation of convective organization is incomplete in regional prediction models, inadequate in global weather prediction models and virtually absent from contemporary climate models. Because convective organization directly affects the processing of water not only within the atmosphere (dynamics-microphysics interaction), but also with the underlying surface (atmosphere surface exchange), a systematic investigation of the coupling among moist convective dynamics, cloud-microphysics and atmosphere-surface exchange is required.

Acknowledgments The National Center for Atmospheric Research is sponsored by the National Science Foundation. We are appreciative of the comments on the manuscript by two anonymous reviewers.

\section{References}

Blackadar AK (1976) Modeling the nocturnal boundary layer. Preprints of the third symposium on atmospheric turbulence, diffusion and air quality, Raleigh, NC. Am Meteorol Soc 46-49

Chen F, Dudhia J (2001) Coupling an advanced land-surface/ hydrology model with the Penn State/NCAR MM5 modeling system. Part I: model implementation and sensitivity. Mon Weather Rev 129:569-585

Carbone RE, Tuttle JD, Ahijevych DA, Trier SB (2002) Inferences of predictability associated with warm season precipitation episodes. J Atmos Sci 59:2033-2056

Done J, Davis CA, Weisman M (2004) The next generation of NWP: explicit forecasts of convection using the weather research and forecasting (WRF) model. Atmos Sci Lett 5:110-117

Dudhia J (1989) Numerical study of convection observed during the winter monsoon experiment using a mesoscale two-dimensional model. J Atmos Sci 46:3077-3107

Dudhia J (1996) A multi-layer soil temperature model for MM5. Preprints, the sixth PSU/NCAR mesoscale model users's workshop, 22-24 July 1996, Boulder, CO, pp 49-50. Available from http://www.mmm.ucar.edu/mm5/mm5v2/whatisnewinv2.html
Dudhia J, Gill D, Manning K, Wang W, Bruyere C (2003) PSU/ NCAR Mesoscale modeling system tutorial class notes and user's guide: MM5 modeling system version 3. Available from http://www.mmm.ucar.edu/mm5/documents/tutorial-v3-notes. html

Hong S-Y, Pan H-L (1996) Nonlocal boundary layer vertical diffusion in a medium-range forecast model. Mon Weather Rev 124:23222339

Lanicci JM, Carlson TN, Warner TT (1987) Sensitivity of the Great Plains severe-storm environment to soil-moisture distribution. Mon Weather Rev 115:2660-2673

Liu C-H, Moncrieff MW (2007) Sensitivity of cloud-resolving simulations of warm-season convection to cloud microphysics parameterizations. Mon Weather Rev 135:2854-2868

Liu C-H, Moncrieff MW, Tuttle JD, Carbone RE (2006) Explicit and parameterized episodes of warm-season precipitation over the Continental United States. Adv Atmos Sci 23:91-105

Moncrieff MW, Liu C-H (2006) Convective organization in prediction models at $10 \mathrm{~km}$ grid-spacing. J Atmos Sci 63:3404-3420

Olson DA, Junker NW, Korty B (1995) An evaluation of three decades of quantitative precipitation forecasting at the Meteorological Operations Division of the National Meteorological Center. Weather Forecast 10:498-511

Oncley SP, Dudhia J (1995) Evaluation of surface fluxes from MM5 using observations. Mon Weather Rev 123:3344-3357

Segal M, Arritt RW, Clark C, Rabin R, Brown J (1995) Scaling evaluation of the effect of surface characteristics on potential for deep convection over uniform terrain. Mon Weather Rev 123:383-400

Shaw BL, Pielke RA, Ziegler CL (1997) A three-dimensional numerical simulation of a Great Plains dryline. Mon Weather Rev 125:1489-1506

Tao W-K, Simpson J (1993) The Goddard Cumulus ensemble model. Part I: Model description. Terr Atmos Ocean Sci 4:19-54

Trier SB, Chen F, Manning KW, LeMone MA, Davi CA (2008) Sensitivity of the PBL and precipitation in 12-day simulations of warm-season convection using different land surface models and soil wetness conditions. Mon Weather Rev 136:2321-2343

Trier SB, Davis CA, Ahijevych DA, Weisman ML, Bryan GH (2006) Mechanisms supporting long-lived episodes of propagating nocturnal convection within a 7-day WRF model simulation. J Atmos Sci 63:2409-2435

Zhang D-L, Anthes RA (1982) A high-resolution model of the planetary boundary layer-sensitivity tests and comparisons with SESAME-79 data. J Appl Meteorol 21:1594-1609

Zhang J, Wang W-C, Leung LR (2008) Contribution of landatmosphere coupling to summer climate variability over the contiguous United States. J Geophys Res 113:D22109. doi: 10.1029/2008JD010136 